\title{
Clinical outcomes of a cohort of patients with central nervous system metastases from thyroid cancer
}

\author{
Joana Simões-Pereira, Daniel Macedo and Maria João Bugalho \\ Endocrinology Department, Instituto Português de Oncologia de Lisboa, Francisco Gentil, \\ Lisboa, Portugal
}

\begin{abstract}
Introduction: Metastases to central nervous system ( $\left.\mathrm{M}_{1}-\mathrm{CNS}\right)$ are rarely reported in thyroid cancer (TC) patients. We aimed to characterize patients with $\mathrm{M}_{1}$-CNS from TC followed in our department.

Methods: Review of the medical records of 27 patients with TC-related $\mathrm{M}_{1}$-CNS. Results: Mean age at TC diagnosis was $56.9 \pm 19.1$ years. Papillary TC $(55.6 \%)$ was the commonest histological type, followed by poorly differentiated $(18.5 \%)$, medullary
\end{abstract}

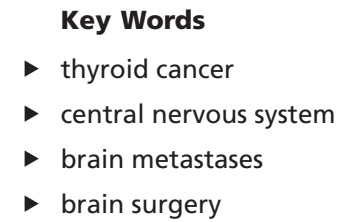

Endocrine Connections (2016) 5, 82-88

\section{Introduction}

Thyroid cancer usually has a favorable prognosis with a reported 10-year survival for differentiated and medullary thyroid carcinoma of approximately $80-95 \%$ (1) and $68-85 \%(2,3)$, respectively. Distant metastases occur in a minority (4-15\%) of these patients $(4,5,6,7,8)$, lungs being the most commonly affected organ (9). Metastases to central nervous system (CNS) are unusual, occurring in $1 \%$ of the patients with thyroid cancer $(10,11,12)$. In contrast with lung involvement, CNS metastases can cause acute disabling symptoms and a marked reduction of patients' survival. International guidelines (13) recommend surgical resection of CNS metastases regardless of its radioactive iodine (RAI) avidity. Those patients not eligible for surgery may undergo stereotaxic radiosurgery (SRS) or whole-brain radiotherapy (WBR).
RAI can be considered for iodine-avid CNS metastases, under glucocorticoid therapy to minimize the TSHinduced effects and the inflammatory process related with RAI.

We aimed to characterize a series of 27 patients with CNS metastases from thyroid cancer in terms of demography, histological features of the primary tumor, diagnostic approach, treatment modalities and clinical outcomes.

\section{Subjects and methods}

Retrospective analysis of patients referred to a single center and identified through the South Regional Cancer

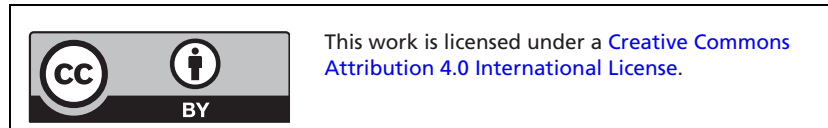


Register of Portugal, and the database of our department. Histological diagnosis of thyroid cancer, of any type, and CNS metastases (encephalic parenchyma involvement and/or leptomeningeal carcinomatosis) from this tumor were considered as inclusion criteria.

Patients with coexisting malignant neoplasms and/ or CNS involvement due to skull bone metastases were excluded from analysis. Finally, clinical records were reviewed to evaluate the demographic characteristics, clinical presentation, diagnostic approach, therapeutic modalities and clinical outcome.

The results presented herein resulted from a retrospective study based on the analysis of clinical files, according to the rules established by the Local Ethics Committee. This study was approved by the Ethics Committee of Instituto Português de Oncologia de Lisboa, Portugal. The results presented in our manuscript resulted from a retrospective study based on the analysis of clinical files, according to the rules established by the Local Ethics Committee. In many cases, the patients had already passed away, so it was not possible to collect the consent forms in these cases.

Statistical analysis was performed using IBM SPSS Statistics, version 21. Mann-Whitney test was used to compare means, which were described as mean \pm S.D. and medians were reported as median (minimum-maximum). Survival after CNS metastases was calculated with KaplanMeier method, and log-rank test was used for univariate analysis. A two-sided $P<0.05$ was considered significant.

\section{Results}

Twenty-seven patients with CNS metastases from thyroid cancer were identified, 18 (66.7\%) were women. Median follow-up was 4 (3-49) years. The diagnosis of CNS metastases was established between 1984 and 2014 .

\section{Primary thyroid cancer: age, histological findings, staging and treatment}

Mean age at diagnosis was $56.9 \pm 19.1$ years. Twenty-six patients $(96.3 \%)$ were submitted to total thyroidectomy; from these, $9(34,6 \%)$ were also submitted to any type of neck lymph node dissection. One (3.7\%) had no thyroid surgery. Histological characteristics and staging are shown in Table 1.

All the 4 patients with tumor size $\leq 2 \mathrm{~cm}$ (pT1) presented aggressive histological characteristics: poorly
Table 1 Histological characteristics and staging.

\begin{tabular}{l} 
Characteristics \\
\hline Histological type \\
- PTC \\
Classical variant \\
Follicular variant \\
Macrofollicular variant \\
Classical + follicular \\
variants \\
Classical + columnar \\
variants \\
Tall-cell variant \\
Follicular + solid +cribiform \\
variants \\
- FTC \\
- HCC \\
- MTC \\
- PDTC \\
Multifocality \\
Angioinvasion \\
Extrathyroidal extension \\
Resection \\
R0|R1|R2|Rx \\
Stage at diagnosis \\
- T \\
pT1|pT2|pT3|pT4|pTx \\
- N \\
pN0|pN1a|pN1b|pNx \\
- M \\
M1|M0/x \\
\hline
\end{tabular}

Number of patients (percentage)

$15(55.6 \%)$

$6(22.2 \%)$

$4(14.8 \%)$

$1(3.7 \%)$

$1(3.7 \%)$

$1(3.7 \%)$

$1(3.7 \%)$

$1(3.7 \%)$

$2(7.4 \%)$

$2(7.4 \%)$

$3(11.1 \%)$

$5(18.5 \%)$

$7(25.9 \%)$

$16(59.2 \%)$

$13(48.1 \%)$

$9(33.3 \%)|5(18.5 \%)| 5$

$(18.5 \%) \mid 8(29.6 \%)$

$4(14.8 \%)|2(7.4 \%)| 8$

$(29.6 \%)|8(29.6 \%)| 5(18.5 \%)$

$5(18.5 \%)|3(11.1 \%)| 6$

$(22.2 \%) \mid 13(48.1 \%)$

$11(40.7 \%) \mid 16(59.3 \%)$

differentiated areas in 2 and angioinvasion, multifocality and lymph node metastases in 3.

Further to surgery, 22 out of 24 patients (92.0\%) with thyroid cancer from the follicular epithelium underwent radioactive iodine (RAI) treatment. Worth of note was a patient who was submitted to six RAI treatments (total ${ }^{131}$ I activity of $\left.575.5 \mathrm{mCi}\right), 5$ after the diagnosis of CNS metastases (patient 8, Table 2).

\section{CNS metastases: diagnosis, therapeutic approaches and clinical outcome}

Of the eleven (40.7\%) patients who already had distant metastases at diagnosis, in 3, (11.1\%) the CNS metastases were the first manifestation of the disease. Median interval between the diagnosis of thyroid cancer and CNS metastases was 44 (0-513) months independently of the histological type. This interval was not different between the patients with different tumor's histological type $(P=0.620)$. Mean age at diagnosis of CNS metastases

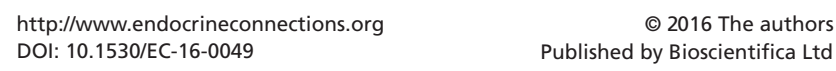


Table 2 CNS metastases-directed therapeutic approaches.$$
\text { . }
$$
concomitantly lung and bone metastases (mainly in concomitantly lung and bone by $74.1 \%$ of patients, were headaches and dizziness. In the remaining cases, patients were asymptomatic, and the diagnosis was disclosed by imaging examinations during restaging.

Sixteen patients (59.3\%) had a single CNS metastasis. Mean size of the dominant metastasis was $30.4 \pm 15.5 \mathrm{~mm}$.

CNS metastases-directed therapeutic approaches were offered to 20 patients and are summarized in Table 2. Of those 17 (62.7\%) who were submitted at some point to WBR, 2 (7.4\%) developed alopecia, 1 (3.7\%) suffered an ischemic stroke and 1 (3.7\%) cerebral demyelination.

Systemic cytotoxic chemotherapy was offered to 4 (14.8\%) patients: doxorubicin + cisplatin (cases 8 and 19, Table 2), capecitabine (patient 3, Table 2) and paclitaxel (case 18, Table 2). One of these patients (case 19, Table 2) had been previously treated with tyrosine kinase inhibitors (TKIs) (7 months with sorafenib and 1 year with sunitinib) and CNS metastases developed under this treatment.

\begin{tabular}{|lr}
\hline http://www.endocrineconnections.org & ○ 2016 The authors \\
DOI: $10.1530 /$ EC-16-0049 & Published by Bioscientifica Ltd
\end{tabular}

\begin{tabular}{|lr}
\hline http://www.endocrineconnections.org & ○ 2016 The authors \\
DOI: $10.1530 /$ EC-16-0049 & Published by Bioscientifica Ltd
\end{tabular}

\begin{tabular}{|c|c|c|c|c|c|c|}
\hline & $\begin{array}{l}\text { Histological } \\
\text { type }\end{array}$ & Gender & $\begin{array}{c}\text { Age at } \\
\text { CNS-M1 } \\
\text { diagnosis }\end{array}$ & $\begin{array}{l}\text { CNS-M1 } \\
\text { single/ } \\
\text { multiple }\end{array}$ & PS & $\begin{array}{l}\text { Other } \\
\text { distant } \\
\text { metastases? }\end{array}$ \\
\hline 1 & PTC & $\mathrm{F}$ & 78 & Single & 3 & No \\
\hline 2 & PTC & $\mathrm{F}$ & 70 & Multiple & 0 & Yes \\
\hline 3 & PTC & $\mathrm{F}$ & 52 & Multiple & 3 & Yes \\
\hline 4 & PTC & $\mathrm{M}$ & 76 & Multiple & 3 & Yes \\
\hline 5 & PTC & $\mathrm{M}$ & 69 & Single & 2 & Yes \\
\hline 6 & PTC & $\mathrm{F}$ & 66 & Multiple & 3 & Yes \\
\hline 7 & PDTC & $\mathrm{F}$ & 81 & Single & 0 & Yes \\
\hline 8 & PDTC & $\mathrm{F}$ & 40 & Multiple & 1 & Yes \\
\hline 9 & FTC & $\mathrm{F}$ & 26 & Single & 0 & Yes \\
\hline 10 & PTC & $M$ & 50 & Multiple & 3 & No \\
\hline 11 & MTC & $\mathrm{F}$ & 37 & Multiple & 2 & No \\
\hline 12 & PTC & $\mathrm{F}$ & 84 & Multiple & 0 & No \\
\hline 13 & PTC & $\mathrm{F}$ & 61 & Multiple & 1 & Yes \\
\hline 14 & PTC & $\mathrm{F}$ & 61 & Multiple & 1 & Yes \\
\hline 15 & $\mathrm{HCC}$ & $\mathrm{M}$ & 63 & Single & 0 & Yes \\
\hline 16 & MTC & $\mathrm{M}$ & 33 & Single & 0 & Yes \\
\hline 17 & PTC & $\mathrm{F}$ & 80 & Multiple & 1 & Yes \\
\hline 18 & PTC & $\mathrm{F}$ & 45 & Multiple & 0 & Yes \\
\hline 19 & PDTC & M & 44 & Single & 0 & Yes \\
\hline 20 & PTC & M & 59 & Single & 3 & Yes \\
\hline
\end{tabular}


cancer was 59 months and since CNS metastases' detection was 5.0 months. The only factor associated with better survival was surgery to brain metastases $(P=0.012)$. Variables/conditions considered in the analysis are described in Table 3.

Those patients not treated for brain metastases $(n=7)$ had a significant lower median survival compared to those who were submitted to at least one therapy (1 month vs 8 months; $P=0.008)$. Although not statistically significant, these patients were older at brain metastases diagnosis $(70.7 \pm 9.0$ vs $59.0 \pm 17.5$ years; $P=0.162)$. They evidenced a plurimetastatic disease and the majority also presented multifocal CNS lesions with disabling symptoms (confusion, vomits, convulsive crisis, etc.); they died soon after the diagnosis of CNS involvement. Furthermore, in the vast majority of patients, it was not possible to clearly establish whether the cause of death was directly dependent from the progression of CNS metastases or from the disseminated disease progression.

\section{Discussion}

It is generally accepted that CNS metastases from thyroid cancer are rare. However, a recent systematic review by Madani and coworkers (14) revealed that, among 492 patients with differentiated thyroid cancer and rare sites of end-organ distant metastases, the brain was the most commonly affected organ within the rare locations. In 1986, McConahey and coworkers (15) verified that
$15 \%$ of the patients with metastatic papillary thyroid carcinoma developed CNS metastases along their disease course. Furthermore, necropsy studies from patients who died from thyroid cancer $(16,17)$ have also documented a frequency of $9.3-20 \%$ of CNS metastases.

Most patients with CNS involvement presented concomitant distant metastases, mainly in lung and bones. In the present series, $77.8 \%$ of the patients had other metastases at the time of CNS metastases' diagnosis. In other published series, this percentage was even higher (Table 4).

As expected, there was a higher frequency of aggressive tumors such as Hürthle cell carcinoma (HCC), medullary thyroid carcinoma (MTC) and poorly differentiated thyroid carcinoma (PDTC) in this subpopulation of patients with CNS metastases, comparative to the frequencies observed among patients with thyroid carcinoma as a whole. However, the histological subtypes did not influence either the period of time elapsed between the initial diagnosis of thyroid cancer and evidence of CNS metastases $(P=0.595)$ or the median survival (Table 3$)$. In our institution, PTC represents $83.7 \%$ of all thyroid tumors, follicular thyroid carcinoma (FTC) $9.4 \%$, MTC 3.3\% and PDTC 1.4\% (unpublished data).

In most patients with well-differentiated thyroid cancer, angioinvasion and extrathyroidal extension coexisted with multifocality, poorly differentiated areas and/or aggressive variants, like insular, solid and tallcell variants. The few patients lacking angioinvasion/ extrathyroidal extension presented nonetheless aggressive

Table 4 Summary of the series reporting CNS metastases from thyroid cancer.

\begin{tabular}{|c|c|c|c|c|c|c|c|c|c|}
\hline & $n$ & Histological type & $\begin{array}{c}\text { Age at } \\
\text { CNS-M1 } \\
\text { (years) }\end{array}$ & $\begin{array}{l}\text { Other } \\
\text { distant } \\
\text { M1 (\%) }\end{array}$ & $\begin{array}{c}\text { Surgery to } \\
\text { CNS-M1 } \\
(\%)\end{array}$ & $\begin{array}{l}\text { SRS } \\
(\%)\end{array}$ & $\begin{array}{c}\text { WBR } \\
(\%)\end{array}$ & $\begin{array}{c}\text { Survival } \\
\text { after } \\
\text { CNS-M } \\
\text { (months) }\end{array}$ & $\begin{array}{c}\text { Period } \\
\text { between } \\
\text { thyroid } \\
\text { cancer and } \\
\text { CNS-M1 } \\
\text { (months) }\end{array}$ \\
\hline 1. Current study & 27 & $\begin{array}{l}15 \mathrm{P}, 2 \mathrm{~F}, 2 \mathrm{H}, 3 \mathrm{M}, \\
5 \mathrm{PD}\end{array}$ & 62 & 77.80 & 18.50 & 18.50 & 63 & 5 & 44 \\
\hline $\begin{array}{l}\text { 2. Henriques de } \\
\text { Figueiredo et al. (18) }\end{array}$ & 21 & 12 P, F 5, 4 PD & 63 & 85.70 & 47.60 & 9.50 & 71.40 & 7.1 & 32 \\
\hline 3. Bernard et al. (28) & 23 & $\begin{array}{l}9 \mathrm{P}, 2 \mathrm{H}, 1 \mathrm{M} ; 11 \\
\text { unknown }\end{array}$ & 63 & & 52.20 & 65 & 34.80 & 20.8 & 41.8 \\
\hline 4. McWilliams et al. (20) & 16 & $\begin{array}{l}11 \mathrm{P}, 2 \mathrm{~F}, 1 \mathrm{~A}, 1 \mathrm{H}, \\
1 \mathrm{M}\end{array}$ & 47 & 87 & 56.30 & 25 & 62.50 & 17.4 & 77.1 \\
\hline 5. Salvati et al. (29) & 12 & $3 \mathrm{P}, 3 \mathrm{~F}, 5 \mathrm{~A}, 1 \mathrm{M}$ & 51 & 58 & 75 & 75 & & 19.8 & 37.4 \\
\hline 6. Chiu et al. (19) & $\begin{array}{c}47 \\
\text { (38 pre-mortem) }\end{array}$ & $32 \mathrm{P}, 11 \mathrm{~A} 4 \mathrm{M}$ & 59 & 66 & 23.70 & - & 52.60 & 4.7 & 34.8 \\
\hline 7. Samuel and Shah (21) & 15 & $9 \mathrm{~F}, 5 \mathrm{P}, 1 \mathrm{H}$ & 46 & 60 & 40 & - & 40 & 12.4 & 61.8 \\
\hline
\end{tabular}

CNS, central nervous system; CNS-M , central nervous system metastases; F, follicular; $\mathrm{H}$, Hurthle-cell; M, medullary; P, papillary, PD, poorly-differentiated; SRS, stereotaxic radiosurgery; WBR, whole-brain radiotherapy.

http://www.endocrineconnections.org $\quad$ C 2016 The authors
$\begin{array}{ll}\text { DOI: } 10.1530 / E C-16-0049 & \text { Published by Bioscientifica Ltd }\end{array}$

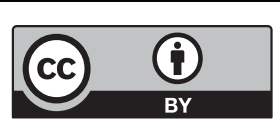

This work is licensed under a Creative Commons Attribution 4.0 International License. 
histopathological features. On the other hand, all the patients with medullary or poorly differentiated thyroid cancer presented aggressive microscopic features.

Although MTC has a different biological behavior from follicular epithelium-derived thyroid cancer, the 3 patients with this subtype of tumor did not evidence a distinctive clinical course, except for a diagnosis of CNS metastases under forty years of age, in 2 out of 3 cases.

We compared our results with those from previous studies including at least 10 patients with CNS metastases from thyroid carcinoma (Table 4). As in other series, the most common histological type was papillary thyroid carcinoma (PTC). Worth of note is one case diagnosed with CNS metastases 42 years after the diagnosis of lung metastases that were the first manifestation of a papillary microcarcinoma (case 3, Table 2).

Median survival after diagnosis of CNS metastases is highly variable among series, probably reflecting different therapeutic approaches. In our series, median survival was less than 10 months after CNS metastases' diagnosis, as observed in two other series $(18,19)$. Although not statistically significant, patients with incidentally diagnosed $\mathrm{M}_{1}$-CNS had a lower survival (incidental CNS diagnosis $=5$ months vs patients with neurological symptoms $=8$ months; $P=0.911$ ). In these patients, the diagnosis was established after clinical suspicion of progression and by imaging tests performed to restaging disease. Therefore, the survival is likely to reflect the unfavorable outcome associated with disseminated disease.

As a rule, the treatment option depends on a multidisciplinary team judgment considering the general condition of the patient, the dissemination of the primary tumor, the location and the number of CNS lesions. In line with previous reports, the only factor associated with better survival was surgery to brain metastases, which in our series was performed in a small number of cases. Surgery was preferably offered to patients with good performance status (PS) and with lesions amenable for resection (unimetastases/oligometastases). All but one evidenced a single CNS metastasis. This fact, combined with a probable better performance status might have contributed to a longer survival among patients submitted to brain surgery. Therefore, at least to the eligible patients, surgery appears as an option that ameliorates the prognosis. Given that this study encompassed a long period, different technical limitations over time cannot be excluded.

Performance status was considered by Henriques de Figueiredo and coworkers (18) as an important prognostic factor in patients with brain metastases from thyroid cancer. These authors verified an overall survival of 27 months when patients' PS was $<2$ and 3 months when PS $\geq 2(P=0.0009)$. Due to the retrospective nature of this study, we could not assess the performance status of patients at the time of brain metastases diagnosis, because this information was not clearly described in the vast majority of the medical files. The prognostic value of unifocality or multifocality of metastases is still not clearly established (19).

Iodine uptake by brain metastases is infrequent (up to $17 \%(19,20,21))$ and, therefore, RAI therapy is not considered as a very efficient approach. However, isolated cases have been reported with satisfactory results (22), as seen in one of our patients who was submitted to 6 RAI treatments (5 after the diagnosis of CNS metastases), following preparation with recombinant thyrotropin, and who evidenced a survival of 51 months. Currently, to avoid prolonged stimulation with $\mathrm{TSH}$, the use of recombinant TSH is recommended (13). RAI-related neurological symptoms have been described, including cerebral edema (23), but this risk may be mitigated with concomitant glucocorticoid therapy.

As in other studies $(18,19,20)$, WBR was not a predictor of longer survival in our series. This therapeutic approach can be proposed to patients for whom surgery is contraindicated, who have disseminated or inaccessible lesions or in whom life expectancy is less than 3 months (19). However, its benefits in disease control must be weighted against its potential neurotoxicity.

Conventional cytotoxic chemotherapy did not offer clear benefits. The use of capecitabine was tried in one patient also without clinical benefit. Capecitabine is an oral prodrug of fluorouracil, previously associated with favorable responses in patients with breast cancer and brain metastases heavily pretreated with other cytostatics including 5-fluorouracil.

Targeted therapies with TKIs are now an alternative for advanced thyroid cancer. The use of these drugs (specifically Sorafenib) has been described in the setting of brain metastases secondary to thyroid cancer $(24,25)$. The single case that we treated with TKIs developed CNS metastases under this treatment. A major concern of this approach is the risk of CNS bleeding associated with the use of TKIs $(26,27)$.

The major limitations of this study are (1) its retrospective nature and (2) recruitment of patients encompassing a large period of time along which technical resources were necessarily different.

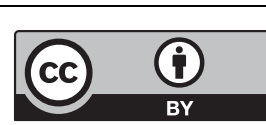

This work is licensed under a Creative Commons Attribution 4.0 International License. 
CNS metastases are rare and present a poor prognosis. Currently, there are no truly effective therapeutic approaches that can improve patients' survival, except for brain surgery, as we observed in our patients. However, we recognize that our sample is small and it may be difficult to get suitable patients for surgery (good clinical status and single or few CNS metastases) at the time of CNS metastases' diagnosis. Therefore, the majority of these patients only benefit of supportive care and/or inclusion in clinical trials directed at treatment of thyroid cancer brain metastases.

\section{Declaration of interest}

The authors declare that there is no conflict of interest that could be perceived as prejudicing the impartiality of the research reported.

\section{Funding}

This study was funded by Associação de Endocrinologia Oncológica (AEO).

\section{References}

1 Schlumberger M. Papillary and follicular thyroid carcinoma. New England Journal of Medicine 1998338 297-306. (doi:10.1056/ NEJM199801293380506)

2 Modigliani E, Cohen R, Campos JM, Conte-Devolx B, Maes B, Boneu A, Schlumberger M, Bigorgne JC, Dumontier P, Leclerc $\mathrm{L}$, et al. Prognostic factors for survival and for biochemical cure in medullary thyroid carcinoma: results in 899 patients. The GETC Study Group. Groupe d'etude des tumeurs a calcitonine. Clinical Endocrinology 199848 265-273. (doi:10.1046/j.13652265.1998.00392.x)

3 Grozinsky-Glasberg S, Benbassat CA, Tsvetov G, Feinmesser R, Peretz H, Shimon I \& Lapidot M. Medullary thyroid cancer: a retrospective analysis of a cohort treated at a single tertiary care center between 1970 and 2005. Thyroid 200717 549-556. (doi:10.1089/thy.2006.0229)

4 Song HJ, Xue YL, Xu YH, Qiu ZL \& Luo QY. Rare metastases of differentiated thyroid carcinoma: pictorial review. Endocrine-Related Cancer 201118 R165-R174. (doi:10.1530/ERC-11-0068)

5 Hoie J, Stenwig AE, Kullmann G \& Lindegaard M. Distant metastases in papillary thyroid cancer. A review of 91 patients. Cancer 199861 1-6. (doi:10.1002/1097-0142(19880101)61:1<1::AIDCNCR2820610102>3.0.CO;2-R)

6 Casara D, Rubello D, Saladini G, Masarotto G, Favero A, Girelli ME $\&$ Busnardo B. Different features of pulmonary metastases in differentiated thyroid cancer: natural history and multivariate statistical analysis of prognostic variables. Journal of Nuclear Medicine 199334 1626-1631.

7 Aggarwal V, Bhargav PR, Mishra A \& Agarwal G. Clinico-pathological characteristics and long-term outcome in patients with distant metastases from differentiated thyroid carcinoma. World Journal of Surgery 200731 246-247. (doi:10.1007/s00268-006-0546-y)

8 Clark JR, Lai P, Hall F, Borglund A, Eski S \& Freeman JL. Variable predicting distant metastases in thyroid cancer. Laryngoscope 2005 115 661-667. (doi:10.1097/01.mlg.0000161337.46892.e0)

9 Mazzaferri EL \& Massoll N. Management of papillary and follicular (differentiated) thyroid cancer: new paradigms using recombinant human thyrotropin. Endocrine-Related Cancer 20029 227-247. (doi:10.1677/erc.0.0090227)

10 Dinneen SF, Valimaki MJ, Bergstralh EJ, Goellner JR, Gorman CA $\&$ Hay ID. Distant metastases in papillary thyroid carcinoma: 100 cases observed at one institution during 5 decades. Journal of Clinical Endocrinology and Metabolism 199580 2041-2045. (doi:10.1210/ jc.80.7.2041)

11 Saad MF, Ordonez NG, Rashid RK, Guido JJ, Hill CSJR, Hickey RC \& Samaan NA. Medullary carcinoma of the thyroid. Medicine 198463 319-342. (doi:10.1097/00005792-198411000-00001)

12 Timothy J, Kerawala C, Brazil L, Bartlett J \& Doshi B. Medullary cell carcinoma of the thyroid: metastases to the central nervous system. European Journal of Surgical Oncology 199521 329-330. (doi:10.1016/ S0748-7983(95)91987-2)

13 Haugen BR, Alexander EK, Bible KC, Doherty GM, Mandel SJ, Nikiforov YE, Pacini F, Randolph GW, Sawka AM, Schlumberger M, et al. 2015 American thyroid association management guidelines for adult patients with thyroid nodules and differentiated thyroid cancer: the American thyroid association guidelines task force on thyroid nodules and differentiated thyroid cancer. Thyroid 201626 1-133. (doi:10.1089/thy.2015.0020)

14 Madani A, Jozaghi Y, Tabah R, How J \& Mitmaker E. Rare metastases of well-differentiated thyroid cancers: a systematic review. Annals of Surgical Oncology 201522 460-466. (doi:10.1245/s10434-014-4058-y)

15 McConahey WM, Hay ID, Woolner LB, van Heerden JA \& Taylor WF. Papillary thyroid cancer treated at the Mayo Clinic, 1946 through 1970: initial manifestations, pathologic findings, therapy, and outcome. Mayo Clinic Proceedings 198661 978-996. (doi:10.1016/ S0025-6196(12)62641-X)

16 Silliphant WM, Klinck GH \& Levitin MS. Thyroid carcinoma and death. A clinicopathological study of 193 autopsies. Cancer 1964 17 513-525. (doi:10.1002/1097-0142(196404)17:4<513::AIDCNCR2820170413>3.0.CO;2-2)

17 Silverberg SG, Hutter RVP \& Foote FW Jr. Fatal carcinoma of the thyroid: histology, metastases, and causes of death. Cancer 1970 25 792-802. (doi:10.1002/1097-0142(197004)25:4<792::AIDCNCR2820250408>3.0.CO;2-P)

18 Henriques de Figueiredo B, Godbert Y, Soubeyran I, Carrat X, Lagarde P, Cazeau AL, Italiano A, Sargos P, Kantor G, Loiseau H, et al. Brain metastases from thyroid carcinoma: a retrospective study of 21 patients. Thyroid 201424 270-276. (doi:10.1089/thy.2013.0061)

19 Chiu AC, Delpassand ES \& Sherman SI. Prognosis and treatment of brain metastases in thyroid carcinoma. Journal of Clinical Endocrinology and Metabolism 199782 3637-3642. (doi:10.1210/ jcem.82.11.4386)

20 McWilliams RR, Giannini C, Hay ID, Atkinson JL, Stafford SL $\&$ Buckner JC. Management of brain metastases from thyroid carcinoma: a study of 16 pathologically confirmed cases over 25 years. Cancer 200398 356-362. (doi:10.1002/cncr.11488)

21 Samuel AM \& Shah DH. Brain metastases in well-differentiated carcinoma of the thyroid. Tumori 199783 608-610.

22 Vrachimis A, Schmid KW, Jürgens H, Schober O, Weckesser M \& Riemann B. Cerebral metastases from thyroid carcinoma: complete remission following radioiodine treatment. Deutsches Arzteblatt International $2013 \mathbf{1 1 0} 861-866$.

23 Datz FL. Cerebral edema following iodine-131 therapy for thyroid carcinoma metastatic to the brain. Journal of Nuclear Medicine 198627 637-640.

24 Krajewska J, Olczyk T, Roskosz J, Paliczk-Cieślik E, Smietana AK, Kaczmarek-Borowska B \& Jarząb B. Treatment with sorafenib in advanced thyroid cancer-a case report. Endokrynologia Polska 2010 $61492-496$.

25 Shen Y, Ruan M, Luo Q, Yu Y, Lu H, Zhu R \& Chen L. Brain metastasis from follicular thyroid carcinoma: treatment with sorafenib. Thyroid 201222 856-860. (doi:10.1089/thy.2011.0419)

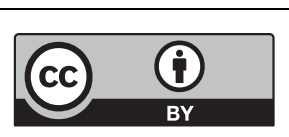

This work is licensed under a Creative Commons Attribution 4.0 International License. 
26 Pouessel D \& Culine S. High frequency of intracerebral hemorrhage in metastatic renal carcinoma patients with brain metastases treated with tyrosine kinase inhibitors targeting the vascular endothelial growth factor receptor. European Urology 200853 376-381. (doi:10.1016/j.eururo.2007.08.053)

27 Chen HX \& Cleck JN. Adverse effects of anticancer agents that target the VEGF pathway. Nature Reviews Clinical Oncology 20096 465-477. (doi:10.1038/nrclinonc.2009.94)
28 Bernad DM, Sperduto PW, Jensen AW \& Roberge D. Stereotactic radiosurgery in the management of brain metastases from primary thyroid cancers. Journal of Neuro-Oncology 201098 249-252. (doi:10.1007/s11060-010-0175-z)

29 Salvati M, Frati A, Rocchi G, Masciangelo R, Antonaci A, Gagliardi FM \& Delfini R. Single brain metastasis from thyroid cancer: report of twelve cases and review of the literature. Journal of Neuro-Oncology $20015133-40$

\section{Received in final form 7 November 2016}

Accepted 17 November 2016

Accepted Preprint published online 17 November 2016
2016 The authors Published by Bioscientifica Ltd

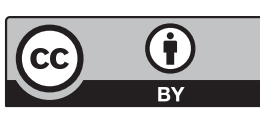

This work is licensed under a Creative Commons Attribution 4.0 International License. 